\title{
Seatbelt and Helmet Use and Associated Factors in a Metropolitan
}

\section{Area}

\author{
Maliheh Dadgarmoghaddam, ${ }^{1}$ Mohammad Khajedaluee, ${ }^{1,}$ Shabnam Niroumand, ${ }^{1}$ Majid Khadem \\ Rezaiyan, ${ }^{1}$ Maryam Abrishami, ${ }^{2}$ Mohammadreza Juya, ${ }^{3}$ and Gholamhasan Khodaee $^{3}$ \\ ${ }^{1}$ Community Medicin Department, Faculty of Medicine, Mashhad University of Medical Sciences, Mashhad, IR Iran \\ ${ }^{2}$ Health Department, State Health Center, Mashhad University of Medical Sciences, Mashhad, IR Iran \\ ${ }^{3}$ Health Department, Mashhad University of Medical Sciences, Mashhad, IR Iran \\ "Corresponding author: Mohammad Khajedaluee, Community Medicine Department, Faculty of Medicine, Mashhad University of Medical Sciences, Mashhad, IR Iran. Tel: \\ +98-5138002388, Fax: +98-51338828560, E-mail: khajedalueem@mums.ac.ir
}

Received 2015 January 06; Revised 2015 April 26; Accepted 2015 May 18.

\begin{abstract}
Background: Despite the mandatory rules and established efficacy of seatbelts and helmets, using them is still unsatisfactory. It seems that there are several factors associated with seatbelt and helmet use in the general public.

Objectives: The aim of this study was to assess the factors associated with the use of seatbelts and helmets.

Patients and Methods: This questionnaire-based, cross-sectional study was a part of the national survey including 1,000 respondents in 2008 - 2010. After compilation of the collected data, analysis was carried out using SPSS version 11.5. In all calculations, P< 0.05 was considered statistically significant.

Results: The research sampling consisted of 500 men and 500 women ranging in age from 17 to 67 years. Seatbelt use differed according to certain factors, such as location $(\mathrm{P}<0.009)$, $\operatorname{sex}(\mathrm{P}<0.001)$, and smoking $(\mathrm{P}<0.04)$. Similarly, the use of helmets also varied according to sex $(\mathrm{P}<0.001)$, smoking $(\mathrm{P}<0.001)$, and tobacco consumption $(\mathrm{P}<0.04)$.

Conclusions: Some factors seem to play a very important role in seatbelt and helmet use; these should be taken into consideration by policymakers.
\end{abstract}

Keywords: Helmet, Mandatory, Laws, Seatbelt

\section{Background}

Traffic accidents (TAs) are now recognized as a "veritable neglected pandemic" $(1,2)$. It is projected that road traffic disability-adjusted life years (DALYs) lost will be the third leading cause of DALYs in the world and the second in developing countries (3). TAs are the major cause of fatalities and serious injuries in Iran and are being considered as one of the high burden issues in this country. According to world health organization (WHO) data for 2011, Iran was ranked fifth in the road traffic accident death rate Namibia, Swaziland, Malawi, and Iraq. The age-standardized death rate caused by road traffic accidents is extremely high in Iran $(44.7 \%$ in 100,000$)(4)$. In Iran, like in many other developing countries, one important factor in the reduction of the mortality rate related to road traffic accidents since 1997 has been the mandatory use of seatbelts and helmet, as human factors play an important role in TAs and their consequences (5). Seatbelt and helmet efficacy has been well documented in the reduction of mortality from TAs by 25 - 67\% (6-8).

Despite the mandatory rules and the established efficacy of seatbelts and helmets, their use is still unsatisfac- tory. Many studies have been performed to assess the use of seatbelts and related outcomes (8-20). It seems that several factors are associated with seatbelt and helmet use in the general public, including gender, age, passenger's status, a low level of education, ethnicity, smoking, alcohol consumption, and so on (21). One study demonstrated that $13.8 \%$ of Iranian people do not use seatbelt, and women tend to use seatbelts less than men (22).

The prevalence of seatbelt usage varies widely and is largely dependent on the laws. According to the results of some studies, the rates of seatbelt use in Iran range from 53 to $70.93 \%$ (23).

\section{Objectives}

The present study was conducted to assess the factors associated with the use of safety belts and helmets among laypeople as a part of national health survey.

\section{Patients and Methods}

The present descriptive, cross-sectional study was carried a part of a national non-communicable risk factor sur- 
vey. It included a random sample of 1,000 people (500 men and 500 women) who were referred to different urban health centers in the Razavi Khorasan province and was conducted in 2008-2010. After giving a code to each participant, 1,000 were selected according to random numbers. All study participants signed an informed consent form. A checklist was completed for all the participants. The main questions that were asked of every participant were as follows: Do you wear seatbelt whenever you travel in the front seat of the car (as a driver or passenger)? Do you use a helmet whenever you get a ride a motorcycle (as the driver or with the driver)?

In this study, tobacco consumption signifies use of hubble-bubble (hookah) or pipe daily. Smoking refers to use of any kind of cigarette daily.

\subsection{Statistical analysis}

After compilation of the collected data, analysis was carried out using SPSS version 11.5, and participants' characteristics were described using percentages, means, and standard deviations (SDs). For data analysis, we used appropriate statistical methods and tests, such as the chisquare, Mann-Whitney, and Kruskal-Wallis tests. In all calculations, $\mathrm{P}<0.05$ was considered statistically significant.

\section{Results}

The studied population consisted of 500 men and 500 women ranging in age from 17 to 67 years (mean \pm SD, 41.9 \pm 14.2 ). Moreover, $53.6 \%$ of our participants were from urban areas. In addition, 432 (43.2\%) of men and $362(36.2 \%)$ of women were employees and housewives, respectively, and only 44 (4.4\%) subjects were unemployed.

Of the respondents, 201 (20.1\%) never sat in the front seat. Of the remaining 799 participants, $47.7 \%$ always used the seatbelt, $36.9 \%$ used it sometimes, and $15.4 \%$ never used it. The use of seatbelts was different according to the variables depicted in Figure 1.

Seatbelt use varied according to job status $(\mathrm{P}<0.001)$. Employees used seatbelts more than others (50.3\%).

The median age in the always group was 43 years, that of the sometimes group was 41, and that of the never group was 38. Statistical analysis showed a significant difference in seatbelt use in different age groups $(\mathrm{P}<0.009$; Figure 2$)$.

Out of 510 people riding motorcycles, $13.5 \%$ were regular helmet users, $21.6 \%$ used helmets sometimes, and 64.9 $\%$ never used them. Helmet use differed according to the variables shown in Figure 3.

Helmet use also varied according to job status $(\mathrm{P}<$ 0.001). Employees used helmets more than others did (46.9\%). The median age in always group was 40 year, that of the sometimes group was 35, and that of the never group was 40 . The statistical analysis showed no significant age difference between these three groups $(\mathrm{P}=0.08)$.

We divided the population into two general groups (those who used seatbelt and helmet and those who did not), and then calculated the odds ratios (ORs; Table 1).

\section{Discussion}

It is considered that wearing seatbelts or helmets in cars is an effective intervention to save lives. According to this study, 88.5\% (413) of males and 79.3\% (263) of females use a seatbelt either sometimes or always. Meanwhile, 56.2 $\%$ of males and $7.7 \%$ of females use a helmet either sometimes or always. According to a study performed in India, based on a single measurement method, the use of safety belts and helmets was more common in males compared to females (24). In another study in US, the same results were seen (25). This could be because in developing countries, including Iran, females drive less frequently than males.

According to this study, 87.9\% (429) of respondents living in urban areas always use seatbelts and helmets, while $37.1 \%$ (66) do so sometimes. These figures drop to $80.3 \%$ (277) and 34\% (113) in rural areas. One similar study done in Malaysia showed that those who drive in city centers are more likely to comply with seatbelt use as compared to those who drive in the country (26). This may have to do with the lower number of risk factors in rural areas as compared to urban ones. High traffic or noise in urban areas can distract the driver's attention, thereby increasing the risk of an accident.

In a review study carried out in 2010 on seatbelt use, it was found that "there are a number of significant risk factors associated with seatbelt nonuse in the general public like male gender, young age, passenger status, risk-taking rural living, low level of education, black or hispanic ethnicity, having few dependents or children, smoking, high speed, alcohol consumption before driving and travelling on secondary roads later in the day" (21). In this study, $92.6 \%$ (100) and 67.2\% (43) of drivers who were smokers used seatbelts and helmets, respectively. This percentage was $80.3 \%$ (277) and 30.5\% (136) in the non-smoker group. One important reason for this could be the more frequent smoking in men who drive more. This status was almost the same for tobacco consumption. Thus, smoking and addiction is another factor that could influence these percentages (Table 1).

This study had some limitations. One limitations was that this was part of a national survey (27). In this regard, the education level of the participants was not available for 
Figure 1. Seatbelt Use

A

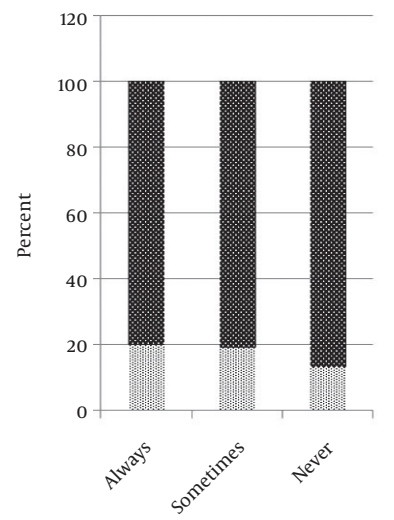

C

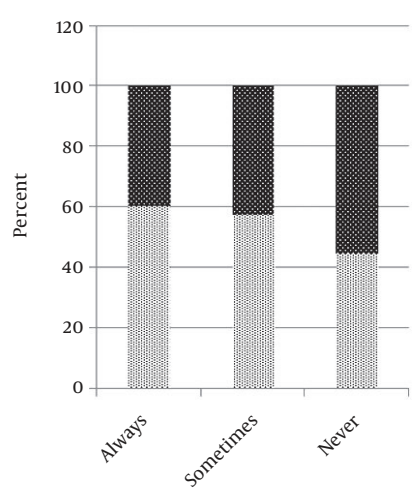

B

Tobacco-
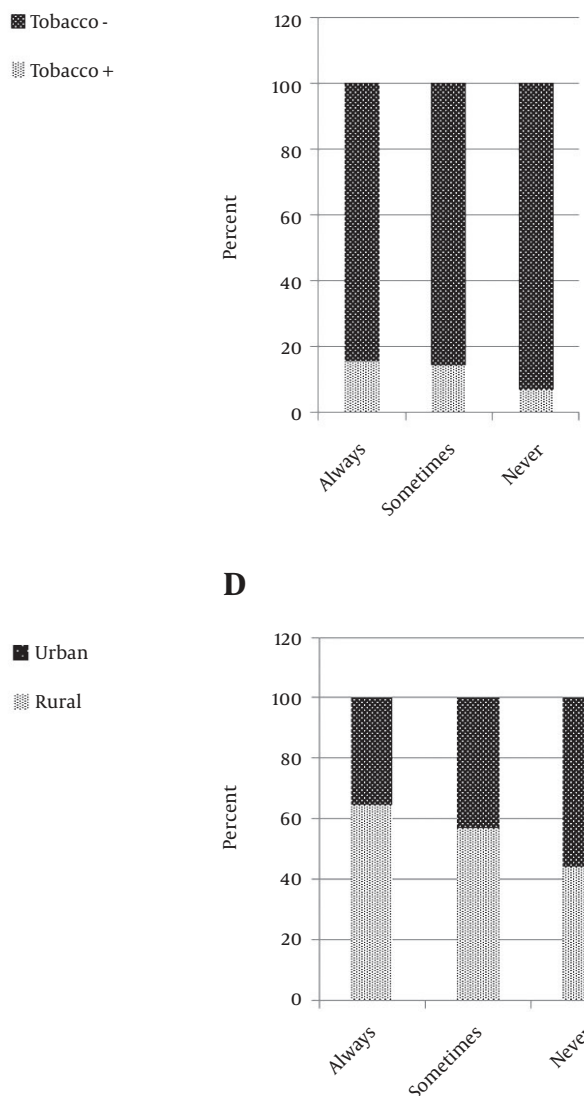

D

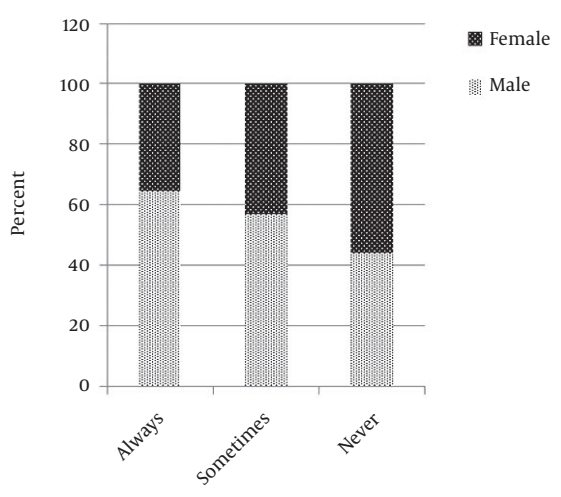

A, location $(P=0.009) ; B$, sex $(P<0.001) ; C$, tobacco consumption $(P=0.26) ; D$, smoking $(P=0.04)$.

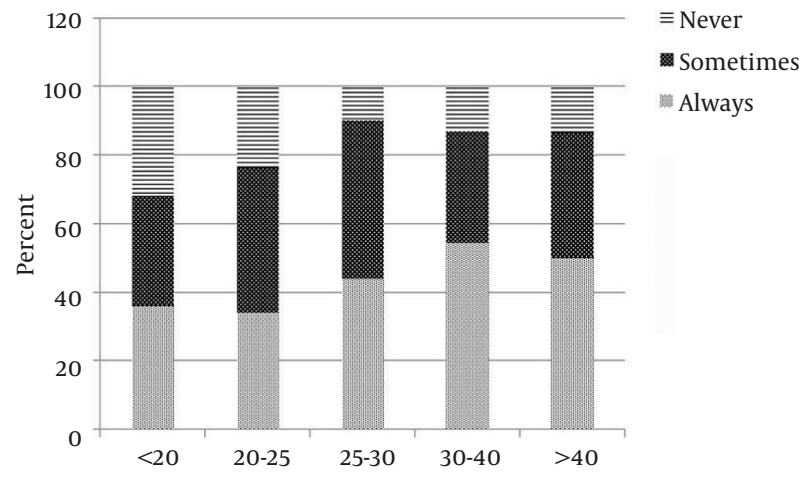

Figure 2. Seatbelt Use in Different Age Groups

us to perform a complementary analysis, and all the analysis was carried out according to the available data. The other limitation was that the questionnaire was completed by the interviewers, and therefore there is a possibility of interviewer bias.

It is necessary to continue to enforce the mandatory 
A

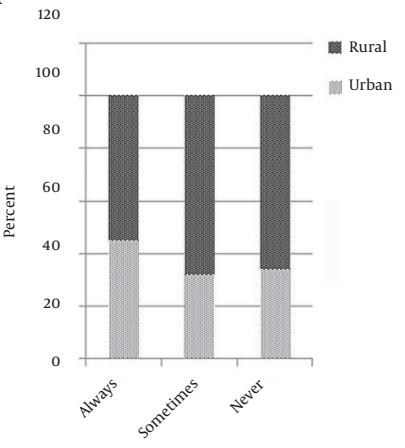

C

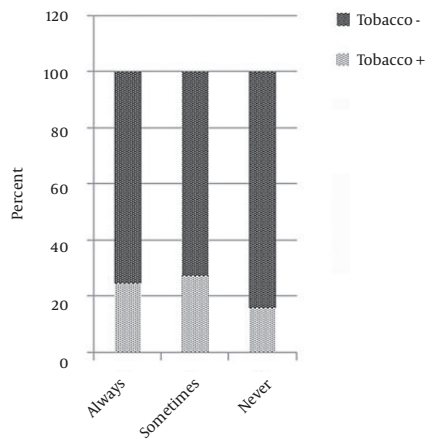

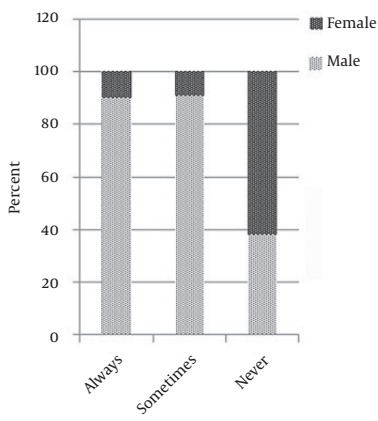

D

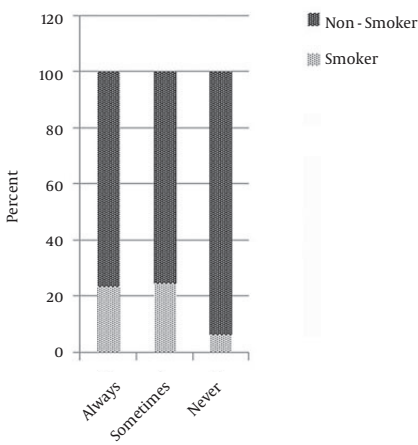

A, location $(\mathrm{P}=0.15) ; \mathrm{B}, \operatorname{sex}(\mathrm{P}<0.001) ; \mathrm{C}$, tobacco $(\mathrm{P}=0.01)$; $\mathrm{D})$ smoking $(\mathrm{P}<0.001)$

Table 1. Odds Ratios for Seatbelt and Helmet use by Location (Urban/Rural), Gender (Male/Female), Smoking, Tobacco

\begin{tabular}{|c|c|c|c|c|}
\hline & \multicolumn{2}{|c|}{ Seatbelt } & \multicolumn{2}{|c|}{ Helmet } \\
\hline & OR & 95\% CI & OR & 95\% CI \\
\hline Location & 1.78 & $1.2-2.6$ & 1.14 & $0.78-1.66$ \\
\hline Gender & 2.007 & $1.36-2.95$ & 15.50 & $8.97-26.7$ \\
\hline Smoking & 2.49 & $1.18-5.27$ & 4.66 & $2.66-8.16$ \\
\hline Tobacco & 1.57 & $0.90-2.75$ & 1.91 & $1.22-2.98$ \\
\hline
\end{tabular}

Abbrevation: CI, Confidence Interval.

rules for seatbelts and helmets by considering which population needs more attention. More research is needed to assess more variables that can affect seatbelt and helmet use, like education or risky behaviors (e.g., alcohol drinking).

\section{Acknowledgments}

We are grateful for assistance from the province health center.

\section{Footnotes}

Authors' Contribution: Maliheh Dadgarmoghaddam designed the study, performed statistical analysis, and drafted the manuscript. Mohammad Khajedaluee designed the study, performed statistical analysis, and drafted the manuscript. Shabnam Niroumand, Majid Khadem Rezaiyan, Maryam Abrishami, Mohammadreza Juya and Gholamhasan Khodaee participated in data acquisition and edited the manuscript. All authors read and approved the final manuscript. 
Financial Disclosure: This manuscript was part of a national survey and we did not receive any financial support.

\section{References}

1. Singh A, Bhardwaj A, Pathak R, Ahluwalia SK. An epidemiological study of road traffic accident cases at a tertiary care hospital in rural Haryana. Indian Journal of Community Health. 2012;23(2):53-5.

2. Dandona R, Mishra A. Deaths due to road traffic crashed in Hyderabad city in India: need for strengthening surveillance. Natl Med J India. 2004;17(2):74-9. [PubMed:15141599].

3. Murray CJL, Lopez AD. Alternative projections of mortality and disability by cause 1990-2020: Global Burden of Disease Study. The Lancet. ;349(9064):1498-504. doi:10.1016/S0140-6736(96)07492-2.

4. World Health Rankings. Road Traffic Accidents. Available at: http://www.worldlifeexpectancy.com/cause-of-death/road-trafficaccidents/by-country/.Accesseddate:8/29/2014.

5. Erfaniantaghvaee MR, Seyyed Nouzadi SM, Alipour Tabrizi A, Dadgarmoghadam M. Human Factors in Traffic Accidents: a Study from a Developing Country. The Veliger. 2015;54(1):1-4.

6. World Health Organization (WHO) and the World Bank report. World report on road traffic injury prevention 2004.. Available from: http: //www.who.int/world-health-day/2004/en.

7. Rutledge R, Lalor A, Oller D, Hansen A, Thomason M, Meredith W, et al. The cost of not wearing seat belts. A comparison of outcome in 3396 patients. Ann Surg. 1993;217(2):122-7. [PubMed: 8439210].

8. El-Sadig M, Sarfraz Alam M, Carter AO, Fares K, Al-Taneuiji HO, Romilly $\mathrm{P}$, et al. Evaluation of effectiveness of safety seatbelt legislation in the United Arab Emirates. Accid Anal Prev. 2004;36(3):399-404. doi: 10.1016/S0001-4575(03)00033-2. [PubMed: 15003585].

9. Beaton SI, Pearson GL, Arnegard RJ, Quinn KD. A field evaluation of the effectiveness of the Virginia safety belt law. Forensic Reports. 1988.

10. Brillhart BA, Jay HM. The impact of Texas state legislation on the use of safety belts. Rehabil Nurs. 1988;13(3):146-9. [PubMed: 3375571].

11. Cope JG, Johnson AW, Grossnickle WF. Behavior engineering proposals:3. Effects on drivers and passengers of a mandatory use law for safety belts.Percept Mot Skills. 1990 ;71:291-8.

12. Alfus GR, Ferrari JR, Arean P, et al. . An examination of the New Yorkmandatory seat belt law on a university campus. Law Hum Behav. 1987;11:63-7.

13. Preusser DF, Williams AF, Lund AK. The effect of New York's seat belt use law on teenage drivers. Accid Anal Prev. 1987;19(2):73-80. [PubMed: 3580093].

14. Preusser DF, Lund AK, Williams AF, Blomberg RD. Belt use by high-risk drivers before and after New York's seat belt use law. Accid Anal Prev. 1988;20(4):245-50. [PubMed: 3415757].
15. Reinfurt DW, Campbell BJ, Stewart JR, Stutts JC. Evaluating the North Carolina safety belt wearing law. Accid Anal Prev. 1990;22(3):197-210. [PubMed: 2393468]

16. Ulmer RG, Preusser CW, Preusser DF, Cosgrove LA. Evaluation of California's safety belt law change from secondary to primary enforcement. Journal of Safety Research. 1995;26(4):213-20. doi: 10.1016/00224375(95)00019-M.

17. Wagenaar AC, Wiviott MB. Effects of mandating seatbelt use: a series of surveys on compliance in Michigan. Public Health Rep. 1986;101(5):505-13. [PubMed:3094082].

18. Williams AF, Wells JK, Lund AK. Shoulder belt use in four states with belt use laws. Accid Anal Prev. 1987;19(4):251-60. doi: 10.1016/00014575(87)90060-1.

19. Escobedo LG, Chorba TL, Remington PL, Anda RF, Sanderson L, Zaidi AA. The influence of safety belt laws on self-reported safety belt use in the United States. Accid Anal Prev. 1992;24(6):643-53. [PubMed: 1388582].

20. Fielding JE, Knight KK, Goetzel RZ. The impact of legislation on self-reported safety belt use in a working population. J Occup Med. 1992;34(7):715-7. [PubMed: 1494964].

21. Intas G, Stergiannis P. Seat belt syndrome: a global issue. Health Sci J. 2010;4:202-9.

22. Heshmati H, Adibmoghaddam S, Khajavi S, Meshkati H. Seat Belt Use and Its Related Factors in Female High School Students in Gorgan, Iran. Health Scope. 2013;2(3).

23. Mohammadzadeh M, Paravar M, Mirzadeh AS, Mohammadzadeh J, Mahdian S. Seat Belt Usage in Injured Car Occupants: Injury Patterns, Severity and Outcome After Two Main Car Accident Mechanisms in Kashan, Iran, 2012. Arch Trauma Res. 2015;4(1):ee22203. doi: 10.5812/atr.22203. [PubMed: 26064867].

24. Chaudhary C, Singh A, Pathak R, Ahluwalia SK, Goel R, Mithra P. Predictors of seatbelt and helmet usage among victims seeking care at emergency department in a tertiary care hospital in rural Northern India. Nepal Journal of Medical Sciences. 2013;2(1):57-61.

25. Shinar D, Schechtman E, Compton R. Self-reports of safe driving behaviors in relationship to sex, age, education and income in the US adult driving population. Accid Anal Prev. 2001;33(1):111-6. doi: 10.1016/S0001-4575(00)00021-X.

26. Kamarudin A, Basil DD KD. a Study on Compliance of Safety Belt Usage Among Car Drivers in District of Batu Pahat, Johor 2006. Available from: http://eprints.uthm.edu.my/1968/1/A_STUDY_ON_ COMPLIANCE_OF_SAFETY_BELT_KAMARUDIN_AMBAK. pdf.

27. Dadgarmoghaddam $M$, Khajedaluee $M$, Khadem-Rezaiyan $M$, Niroumand S, Abrishami M, Joya M. , et al. Risk Factors for Noncommunicable Disease:A Population Based Study in Mashhad (Iran). BJMMR. 2015;7(6):503-11. 